\title{
Ideólogos y expertos en el Perú reciente
}

\author{
Juan Martín Sánchez y Osmar Gonzales** \\ Escuela deEstudios Hispano-Americanos, CSIC. Sevilla \\ y Biblioteca Nacional de Perú
}

\begin{abstract}
En este artículo se contraponen las figuras del ideólogo y el experto que tienen en común el uso del conocimiento y su polémica proximidad a las altas esferas del gobierno estatal. Se esbozan tres decenios de la vida política peruana en que aparecen y desaparecen esas dos figuras, atendiendo a su extracción sociopolitica y a su lugar en las luchas dentro del poder estatal. El movimiento pendular que parecieran haber tenido en las décadas de los setenta y ochenta, entre gobiernos reformistas más ambiciosos en cuanto a producción ideológica y los gobiernos conservadores más pragmáticos, se rompe con la irrupción del gobierno de Fujimori con sus tácticas mafiosas y secretas.
\end{abstract}

En las últimas décadas y a escala mundial el llamado experto o tecnócrata ha adquirido una importancia creciente hasta el punto de poner en tensión los clásicos modelos ilustrados de la política. Si bien su presencia no es absolutamente inédita sí lo es su arrollador protagonismo, siempre asido a las altas esferas del poder, ligado a las instancias últimas de decisión. En un proceso paulatino, el experto ha ido desplazando a ese tipo de intelectual tan cautivante y polémico como es el ideólogo. Éste, atento a los grandes valores que supuestamente deben tutelar a las sociedades, defiende proyectos de formación de comunidad, preocupación que para los expertos resulta irrelevante.

Desde los años del reformismo militar dirigido por el general Juan Velasco Alvarado (1968-1975), hasta el autoritarismo tecno-militar acaudillado por el ingeniero Alberto Fujimori, pasando por la fase conservadora del gobierno militar (comandada por el general Francisco Morales Bermúdez, 1975-1980) y los dos gobiernos constitucionales de la década del ochenta (de Acción Popular, 1980-1985, y el de APRA, 1985-1990), la tensión entre humanistas y expertos por capturar las fantasías del Príncipe ha sido permanente. De una manera amplia que necesita ser constatada con investigaciones más detalladas, podemos afirmar que el papel de los humanistas ha sido pre-

* Autor de los libros La revolución peruana: ideología y práctica política de un gobierno militar, 1968-1975, Sevilla, 2002; y Perú 28 de julio: discurso y acción política el día de Fiestas Patrias, 1969-1999, Sevilla, 2002.

** Autor de Sanchos fracasados. Los arielistas y el pensamiento político peruano, Lima, 1996; y Señales sin respuesta. Los Zorros y el pensamiento socialista en el Perú, Lima, 1999. 
ponderante en los tiempos reformistas y populistas, mientras que el de los expertos lo ha sido en los periodos conservadores y represivos.

Según muchos analistas - y también ciertas evidencias-, el ideólogo, es decir, el intelectual que busca explicaciones generales basándose en valores universales, ha perdido la centralidad que había alcanzado durante los tiempos modernos. Esa influencia sobre la sociedad que le permitía identificar y propugnar ciertos valores aceptados como fundamentales para que ella pudiera mantener su cohesión e identidad. Sin embargo, esta centralidad del intelectual como encarnación de los valores generales de la sociedad ha ido cediendo terreno ante la aparición y progresiva preponderancia de los llamados expertos. Éstos, portadores de intereses particulares, han ido tomando posiciones progresivamente centrales y siempre ligándose a las esferas del poder.

La historia de los expertos es de larga data. Ellos son parte de lo que Alvin W. Gouldner denomina la "nueva clase" que surgió con los tiempos modernos y que a través de los años ha sufrido un proceso de diferenciación interna: por un lado, los intelectuales (humanistas) y, por otro, la intelligentsia (tecnocrática) o expertos. ${ }^{1}$

Los expertos, quienes inicialmente pueden ser definidos como aquellos que son competentes "en alguna cosa en la que otros son incompetentes", ${ }^{2}$ son portadores de un saber técnico y especializado, se guían por principios-medios, en contraste con los ideólogos, quienes definen su actividad gracias a principios-fines. Como señala Norberto Bobbio:3 "lo que, de hecho, distingue al uno del otro es [...] la distinta tarea que tienen en cuanto a creadores o transmisores de ideas o conocimientos políticamente relevantes, es el distinto papel que están llamados a desarrollar en el contexto político". ${ }^{4}$ En la actualidad, los expertos predominan en un horizonte en el que prevalecen la especialización y el profesionalismo. El ámbito privile-

1 Gouldner, Alvin W.: El futuro de los intelectuales y el ascenso de la Nueva Clase, Madrid, 1980.

2 Maldonado, Tomás: ¿Qué es un intelectual? Aventuras y desventuras de un rol, 1998, pág. 35 .

3 Bobbio, Norberto: La duda y la elección. Intelectuales y poder en la sociedad contemporánea, Barcelona, 1998.

4 Bobbio, Norberto: La duda y..., págs. 62-64. Sin embargo, José Antonio Aguilar Rivera tiene razón cuando señala que, en la actualidad, cuando los medios se han convertido en fines — como el mercado, por ejemplo-, tal distinción entre expertos e ideólogos no es tan precisa, puesto que los intelectuales pueden actuar como ambos según circunstancias. No obstante, consideramos que dicha clasificación sigue siendo útil para el tema que estamos desarrollando, a la manera de "tipos ideales", pero siempre con la condición de no entender a una u otra figura de intelectual como irreconciliables entre sí. "El siglo de los intelectuales", Nexos, núm. 252, diciembre, 1992. 
giado de acción de los expertos es el poder, con el que dialoga y al que busca influir en sus decisiones. En sus labores de asesoramiento, los expertos se ubican en un espacio intermedio entre la ciudadanía y los dirigentes. ${ }^{5} \mathrm{~A}$ los expertos, en tanto tecnócratas, lo que los legitima es el ser portadores de un saber especializado, no el apoyo de una mayoría electoral. ${ }^{6}$

Desde el espacio semipúblico en el que se desenvuelve la actividad del experto, se van configurando circuitos de expertos con el objeto de incidir en las políticas públicas y "disciplinar a los agentes económicos y al propio Estado con patrones de análisis y evaluación derivados de modelos y teorías económicas". ${ }^{7}$ La creencia en la supremacía del saber especializado supone, según algunos observadores, el fin de la demagogia que presuntamente encarna el gran intelectual, y abre paso al entronizamiento del realismo que enarbola el conocimiento técno-científico. De esta manera, y según ciertas visiones, la función del intelectual pasa de ser el garante de los valores generales a convertirse - vía los expertos- en el portador de valores particulares. En otras palabras, las funciones tradicionalmente reconocidas a los intelectuales con pretensiones de generalidad hoy se ven severamente cuestionadas, y sus espacios de desenvolvimiento drásticamente reducidos.

En América Latina el experto representa una figura que cuestiona al pasado de la política populista, a la cual se ve con una mirada cargada de prejuicios ideológicos, atendiendo sólo a sus características de manipulación y autoritarismo, sin considerar su contrapeso, es decir, dejando de lado el papel que jugó en la incorporación de los sectores populares a la política y en el reconocimiento de éstos como ciudadanos.

Supuestamente, los expertos no se identifican con ideología alguna y esa es su carta de presentación para legitimarse ante una sociedad que, a su vez, se muestra apática y desconfiada de la política, lo que facilita su acomodo en las esferas de decisión fundamentales. Desde esta ubicación privilegiada, los expertos diseñan las políticas a aplicar, las mismas que se exponen ante la opinión pública como necesarias para el logro del "bien común".

5 Smith, James A.: Intermediarios de ideas. Los "Grupos de Expertos" (Think tanks) y el surgimiento de la nueva élite política, Buenos Aires, 1994.

6 Babb, Sara: "Los profesionistas en el gobierno y el problema de la tecnocracia: el caso de los economistas en México", Estudios Sociológicos, vol. XVI, núm. 48, septiembre-diciembre, México, 1998.

7 Camou, Antonio: "Saber técnico y política en los orígenes del menemismo", Perfiles Latinoamericanos, año 7, núm. 12, junio, México, 1998. 
La política sugerida por el experto se desentiende de los problemas humanos, le interesan más las cifras macroeconómicas, los índices de inflación y las estadísticas. No le resultan incómodas las precarias condiciones en las que vive la mayoría de la población. De esta manera, se produce una dramática distorsión: los hombres convertidos en datos. Su foco de atención son los problemas puntuales, privilegian lo urgente a lo importante y no exhiben ningún interés por proyectar formas nuevas de socialización, ni de imaginar formas políticas de constitución de comunidades. Así, elites desprovistas de una visión de largo plazo, y sociedades presionadas por múltiples carencias configuran la realidad actual de los países latinoamericanos.

En un panorama como el presente, en el que la política se entiende como la solución de urgencias y en el que los tejidos sociales se desvanecen, pensar en alternativas de salidas a la crisis general de América Latina resulta muy difícil. Para hacerlo se necesita no sólo de sujetos sociales (que algunos ven encarnados en la llamada sociedad civil), sino también reconstituir a las elites intelectuales y políticas, y que éstas propongan nuevas maneras de sociabilidad.

\section{Los intelectuales y expertos durante el gobierno militar}

En octubre de 1968, el jefe del comando conjunto de las fuerzas armadas del Perú, el general Juan Velasco Alvarado, tomó el máximo poder institucional de la república al frente de un conjunto de hombres de uniforme y de un proyecto de transformación "integral" de la sociedad peruana: una revolución. El gobierno del Estado quedaría en manos militares hasta el 28 de julio de 1980 cuando fuera entregado al mismo presidente civil que fuera derrocado en 1968, Fernando Belaunde Terry.

Sobre el gobierno militar hay que destacar dos cuestiones. La primera es que la cronología de esos doce años muestra diversos escenarios para el estudio de los intelectuales y los ideólogos en la vida política. No sería correcto hablar del gobierno militar en singular, sino de los gobiernos militares, y su más importante demarcatoria es la distinción entre el gobierno comandado por Velasco Alvarado, hasta el 29 de agosto de 1975, y el dirigido por el general Francisco Morales Bermúdez hasta julio de 1980. La segunda es que, al ser los militares los que dominaban institucionalmente la política, los civiles aparecían en una relación dependiente e indirecta con 
ese poder institucional: eran los militares los que señalaban el carácter de lo civil que nunca alcanzó a tener una dinámica política propia, aunque esto no quiere decir que su participación fuera insignificante.

\section{Intelectuales civiles y militares progresistas: la palabra y la acción}

Carlos Franco encuentra las razones del acercamiento entre la minoría de militares progresistas y un grupo de intelectuales civiles en su común frustración ante el bloqueo del régimen político peruano previo a 1968: "es que los partidos, las elecciones, el Parlamento y el poder Ejecutivo, esto es, las instituciones centrales del régimen político, constituyeron diversas fuentes de frustración para ellos y les verificaron su situación minoritaria y su inserción marginal en el país político". ${ }^{8}$ Esta opinión parece concordar con el apoyo, desde los primeros días, de los líderes de la Democracia Cristiana, Héctor Cornejo Chávez, y del Movimiento Social Progresista, Alberto Ruiz Eldredge o, poco después, luego de regresar del extranjero, del ex-aprista Carlos Delgado.

Con la legitimación que el gobierno militar ganó por la nacionalización de la International Petroleum Company (IPC), otros grupos políticos expresarían su apoyo explícito al proceso, entre ellos el Partido Comunista del Perú, la Central General de Trabajadores del Perú — de dirección comunista-, Acción Popular Socialista de Manuel Seoane e, incluso, parte de la agrupación de derecha Unión Nacional Odrísta. Pero serían los socialprogresistas, los demócratacristianos y, en parte, el PCP los que mayor número de asesores relevantes aportarían al proceso.

Las condiciones del encuentro estarían sujetas al proceso mismo de reformas, cuyo ritmo y orientaciones básicas estaban dadas desde el sector militar. Para tener alguna influencia en la implementación de las reformas había que llegar a Velasco a través de alguno de sus asesores civiles más cercanos - Cornejo Chávez y Carlos Delgado, hombres muy estimados por el general- Esta necesidad de relacionarse con alguno de los coroneles, generales o con el propio Velasco para orientar en algo las políticas públicas, traería consigo un cierta red de influencias, no siempre ideológicamente estructurada, que aumentaba la personalización del poder y que

8 Franco, Carlos: "Los significados de la experiencia velasquista: forma política y contenido social”, en El Perú de Velasco, Tomo II, Lima, 1983, pág. 330. 
era objeto de críticas de "infiltración" comunista o conservadora. En realidad, se trataba de la ampliación de la minoría gobernante sin otra organización política que el patronazgo del mismo gobierno castrense.

Los lugares del encuentro entre militares y civiles determinarían, en gran medida, los rasgos de composición y la dinámica de funcionamiento de esa nueva minoría ampliada. Esos lugares fueron la propia administración pública - con todo su legado de funcionarios y clientelismos burocráticos-, los departamentos más afines al diseño de las reformas — como el Instituto Nacional de Planificación-, los organismos creados por el propio proceso - el Sistema Nacional de Apoyo a la Movilización Social (Sinamos) o el Instituto Nacional de Cultura-, las comisiones ad hoc de las distintas reformas estructurales - la Comisión de Reforma de la Educación, el Consejo Nacional de Justicia - o los directorios de los periódicos expropiados en 1974.

Difícilmente se podría decir que el conjunto de asesores civiles - con la tibia excepción del grupo que trabajaba en Sinamos, bajo la dirección de Carlos Delgado- constituyese un grupo homogéneo y concertado en su trabajo. ${ }^{9}$ La fuerte personalidad y prestigio intelectual y político de muchos de ellos los hacían muy reticentes al comportamiento orgánico. En general, desde todos los ministerios se convocaba la colaboración de asesores civiles, la mayoría de la veces entre los altos funcionarios y otras entre profesionales, expertos o intelectuales de reconocido prestigio. ${ }^{10}$ El Comité de Oficiales Asesores de la Presidencia (COAP) sería el organismo que solicitaría más asesoramiento civil de alto nivel, pues tenía a su cargo la responsabilidad de la preparación, la revisión de las leyes y el diseño del desarrollo de las reformas. Si durante algún tiempo, estos asesores quisieron ser los ideólogos o intelectuales del proceso, pronto resultaron ser los tecnólogos del discurso oficial, aunque con el cierto margen de acción que le permitía la heterogeneidad y amplitud de ese mismo discurso.

9 Entre otros trabajos, el de Kruijt, Dirk: La revolución por decreto, Lima, 1988. Para el tema de Sinamos: Scott Palmer, David: Revolution from above: military government and popular participation in Peru, Cornell, 1973.

10 Así llegaron al proceso personas como Otoniel Velasco, director del INP, junto con Carlos Delgado — quien luego dejaría este instituto para ser asiduo asesor del COAP y director del Sinamos-, el ingeniero Luis Guilfo o, al Ministerio de Industria, el ingeniero Ángel de las Casas. Para localizar a muchos de estos asesores se pueden consultar los cuatro volúmenes de la Cronología Política publicada por DESCO; el libro de Dirk Kruijt, ya mencionado, otros textos publicados por los protagonistas. También Juan Martín Sánchez realizó algunas entrevistas personales con varios de esos asesores y conocedores del proceso como Francisco Guerra García, Carlos Franco, Hugo Neira, Ricardo Morales, Luis Alberto Ratto, Guillermo Rochabrún, Julio Cotler, Francisco Verdera. 
Un caso tal vez especial en cuanto a intensidad, calidad y autonomía de los asesores civiles se encuentra en el sector educación. En éste se inició una casi utópica reforma de todo el sistema cuando en el Perú las políticas educativas apenas habían superado el nivel de expansión de la matrícula escolar y de la alfabetización de las clases populares.

La Comisión de Reforma de la Educación presidida por Emilio Barrantes significó un campo abierto por el gobierno militar a la participación de los civiles que se dio con gran vigor, aunque al final también tuvieron que plegarse a las directrices económicas y las decisiones políticas emitidas desde el gabinete.

Otra comisión, aunque de corta vida y demasiado indefensa ante las decisiones de los militares, pero que puede servir como ejemplo de la amplia gama de apoyos civiles que tuvo el gobierno de Velasco, fue el Comité Provisional de la Organización Política de la Revolución Peruana, creado el 1 de agosto de 1975. Ese Comité puede tomarse como una fotografía de hasta dónde había llegado la red de la participación sociopolítica en el proceso, tanto en razón de las instituciones representadas y de las personas integradas, como de las dificultades de su constitución, sus conflictos internos y su sometimiento a las decisiones de los militares. ${ }^{11}$

No es fácil establecer las posiciones básicas de tantos y tan diferentes asesores y apoyos civiles, aunque sí se puede afirmar que eran personas muy implicadas en los debates ideológicos que se estaban dando en el Perú. En general, procedían de cierto dominio ideológico socialista y revolucionario, eran personas de ámbitos profesionales y académicos que vieron en las ofertas de reformas estructurales del gobierno militar una oportunidad para salir del bloqueo en que pensaban se encontraba el país. Franco resume las dos maneras en que se pensó el proceso dentro de aquella minoría de militares y civiles: "mientras el grupo militar de Velasco organizó su reflexión desde el Estado y la orientó por la necesidad de construir un Estado nacional, los grupos civiles desarrollaron su pensamiento desde la sociedad y lo orientaron por la finalidad de democratizarla substantivamente". ${ }^{12}$

Estas dos maneras de pensar la transformación del Perú tienen que ver mucho con ese país heterogéneo en el que no se localiza un grupo político hegemónico que integrase poder y legitimidad; en el que el principal poder

11 Pease García, Henry, y Filomeno, Alfredo: Perú 1975, Cronología Política, tomo IV, Lima, 1977, pág. 1527.

12 Franco, Carlos: "Los significados...”, pág. 332. 
coercitivo, el ejército, se distanciaba de los poderes económicos, mientras los intelectuales renovadores no lograban seducir ni a esos poderes económicos ni a las mayorías populares. Ambas trayectorias confluyeron en una "estrategia" que, partiendo de los preparativos anteriores al golpe y los acuerdos institucionales en la cumbre de las fuerzas armadas del 3 de octubre, fue fundamentalmente orientada por el general Velasco, el general José Graham Hurtado (presidente del COAP y buen amigo de Velasco) y Carlos Delgado. Ellos eran el vértice de una red sumamente jerarquizada en la que se integraban diferentes grupos de militares, ministros y asesores civiles desde sus puestos en la administración pública. En esa red, Franco destaca el papel jugado por el COAP, el INP y el Sinamos —organismos directamente dependientes de Velasco y de carácter multisectorial-, en el desarrollo de una estrategia de transformación global del Perú, desde la que se ordenaban a los sujetos según los espacios de poder. ${ }^{13}$

Fuera de estas relaciones directas entre militares y civiles se encontraba una amplia gama de intelectuales que defendían sus diversas posiciones políticas con extraordinaria fuerza. Se podían ver a famosos escritores que, con matices, apoyaban al gobierno, como Julio Ramón Ribeyro, o intelectuales como Bravo Bresani quienes, sin asumir un cargo directo en el Estado, defendían el proceso. Pero también había un nutrido grupo de intelectuales que se distanciaban, tras cierto reconocimiento, del gobierno militar como Pablo Macera, Guillermo Thorndike, Mario Vargas Llosa y Mirko Lauer.

Los grupos cristianos progresistas también se constituyeron en una importantísima fuente de discusión y debate con personalidades tan destacadas como el propio cardenal Juan Landázuri, los obispos José Dammert y Luis Bambarén, Felipe McGregor desde la Universidad Católica, Gustavo Gutiérrez - el teólogo peruano de mayor prestigio dentro de la Teología de la Liberación - en la universidad y el movimiento popular, y Romero Luna Victoria. La creación de la Oficina Nacional de Información Social (ONIS) jugaría un muy importante papel durante todo este periodo y los siguientes.

Sin lugar a duda, también hubo intelectuales con una postura totalmente contraria al gobierno militar como Julio Cotler o Aníbal Quijano (quienes fueron deportados por el velasquismo) y los que mantenían posturas aun más enfrentadas desde el extranjero, como Pedro Beltrán (direc-

13 Ibídem, pág. 335-378 
tor de La Prensa, órgano de expresión de los agroexportadores) o algunos líderes de Acción Popular. Los sectores próximos al Partido Aprista se limitaron a "esperar y ver", mientras que el empresariado trataba de influir en las políticas del gobierno, que tanto favoreció a los industriales, e hicieron de la Conferencia Anual de Ejecutivos (CADE) una importante plataforma de difusión de sus planteamientos llegando al enfrentamiento abierto con el propio presidente Velasco como hizo el empresario Walter Piazza.

El asunto de los apoyos intelectuales y la difusión de opiniones en torno a la actuación del gobierno militar no fue nunca un tema menor en la agenda, especialmente cuando los muchos esfuerzos por lograr un mayor apoyo social a las reformas no lograron mayores resultados. Se publicaría una gran cantidad de documentos y revistas, especialmente por parte del Sinamos, en defensa del proceso contra la opinión de los intelectuales y partidos de oposición. Y como último recurso en este enfrentamiento, siempre se disponía de la clausura de revistas semanales como Oiga o Caretas, e incluso la deportación de destacadas personalidades. Para mediados de 1975, el gobierno de Velasco ya estaba muy desgastado y se veía venir el cambio en la presidencia. Con la masiva deportación del 5 de agosto de ese año, la relación entre militares e intelectuales se quebraría sin muchas posibilidades de ser recuperada. Incluso, una personalidad tan destacada como Ruiz Eldredge, dimitiría como director de Expreso en protesta por la depuración que se estaba llevando a cabo bajo la cobertura de una supuesta "infiltración comunista". ${ }^{14}$

\section{Ordenando la retirada a los cuarteles: llegan los civiles conservadores}

El 29 de agosto de 1975, el primer ministro, el general Francisco Morales Bermúdez, dio un golpe de Estado e inició lo que se ha conocido como "la segunda fase", caracterizada por un institucionalismo militar más centrado en los cuarteles, donde la Junta Militar asumió mayor protagonismo en el gobierno. El contexto era marcado por la profundización de la crisis económica, el fortalecimiento de la movilización popular y el distanciamiento de los intelectuales, en un ambiente de mayor represión y, luego, de inicio de la transición hacia la democracia.

14 Pease García, Henry: Los caminos del poder. Tres años de crisis en la escena política, Lima, 1979, págs. 58-63. 
Morales Bermúdez siempre fue el máximo representante del militar de carrera: institucionalista, con formación economía y actitud fuertemente tecnócrata. No se implicó en los preparativos del alzamiento de 1968 sino que se sumó al proceso con posterioridad. Antes, había participado en el gobierno de Fernando Belaunde Terry como apoyo castrense ante la debilidad gubernamental. La trayectoria del nuevo Jefe de Estado nos da un boceto bastante acertado de lo que fue su gobierno.

Los civiles ya no alcanzarían la calidad y autonomía que tuvieron durante la primera fase y aunque siguieron los apoyos de anteriores civiles afines al gobierno, estos concluirían en marzo de 1976, cuando el gobierno sustituyó a todos los directores de los periódicos por sus críticas al forzado retiro de los generales Leonidas Rodríguez Figueroa y José Graham Hurtado. Los nuevos directores, como Luis Jaime Cisneros - hermano del ministro del interior durante el "estado de emergencia" proclamado por el gobierno en el intento de controlar las convocatorias de paro nacional en julio de 1977 y mayo de 1978-, conducirían a la prensa estatizada a los máximos niveles de manipulación y entreguismo.

Viejos conocidos reaparecieron en la escena marcando nuevos lineamientos y abriendo espacios para una "transición conservadora". Se levantaron voces como la del ex-ministro de economía Manuel Ulloa o la del dirigente del Partido Popular Cristiano (PPC) Luis Bedoya Reyes, que criticaban al primer ministro, el general progresista Fernández Maldonado que estuvo con Velasco desde 1968 aunque luego apoyó su derrocamiento--, por querer ser el Salvador Allende del Perú.

También fueron reapareciendo los líderes del APRA con un matizado apoyo al nuevo gobierno que revelaba su estrategia frente a la muy previsible convocatoria de elecciones. Y tras el fracaso del ministro de economía, general Luis Barúa Castañeda, en el intento de frenar la crisis económica y recabar el apoyo de la burguesía, llegaba al gabinete el primer civil, nada menos que el empresario Walter Piazza, quién se opuso abiertamente a la orientación "participacionista" y social de la primera fase. A su vez, Piazza fue reemplazado en junio de 1977, en medio de un espectacular crecimiento del movimiento popular, pero el gobierno parecía tener ya claro sus objetivos fundamentales: negociar con el FMI la aplicación de las políticas de ajuste económico y ordenar la retirada de los militares del gobierno sin abandonar sus posiciones de privilegio en la escena política.

Para los anteriores objetivos no se necesitaba de la creación de un cuerpo de asesores civiles como en la primera fase. Bastaba con algunos 
portavoces más o menos independientes que, desde la crítica a las reformas velasquistas, lidiaran con la creciente oposición de izquierdas. La administración pública sería depurada de anteriores asesores y organismos como el Sinamos o la Confederación Nacional Agrícola (CNA) serían clausurados.

La convocatoria a elecciones para una "asamblea constituyente", exclusivamente elegida para la redacción de una nueva Constitución Política del Estado, fue anunciada por el presidente el 28 de julio de 1977, tras el contundente paro nacional del día 19 de ese mismo mes. La dinámica política que abrió este anuncio y el decreto de convocatoria de elecciones para el 4 de junio de 1978, colocó al gobierno en una situación de mayor aislamiento; por su parte, los intelectuales tratarían de definir sus posibilidades políticas frente a las elecciones. En ese escenario, serían los tecnócratas nacionales y los procedentes de los organismos multilaterales, los que adquirieron una extraordinaria relevancia en el manejo de las políticas del gobierno.

El 13 de abril de 1978 la Misión Holandesa, encargada de hacer un diagnóstico de la situación económica del país y sus posibles soluciones, entrega su informe en el que recomienda la negociación con el FMI, la eliminación de los déficit de Petroperú y otras empresas públicas, y el retorno al gobierno civil. ${ }^{15}$ Pocas semanas después se pondrían en marcha las diversas medidas del paquete de ajuste económico. El día 15 de mayo, Javier Silva Ruete fue nombrado ministro de economía - autor en la sombra del plan de ajuste- junto con Eduardo Lanatta Piaggio en el Ministerio de Industria y Manuel Moreyra Paz Soldán al frente del Banco Central de Reserva. Los acuerdos con el FMI llegarían pronto, así como el apoyo de Estados Unidos vía AID. El prestigio de Silva Ruete y Moreyra en el sistema financiero internacional les otorgaba un alto grado de autonomía frente a los militares y sus pretensiones de gastos en armamento, o frente a los que pretendían una cierta reactivación económica desde el ministerio de industria. ${ }^{16}$

De otra parte, continuaban las protestas del movimiento popular que lograron una total unidad sindical en la convocatoria y realización del paro nacional de 48 horas los días 22 y 23 de mayo de 1978, poco antes de las elecciones. La represión policial se acentuó y el gobierno calificó los suce-

15 Ibídem, pág. 281

16 Cotler, Julio: 'Las intervenciones militares y la 'transferencia del poder a los civiles' en el Perú”, en O’Donnel, Guillermo, Schmitter, Philippe C., y Whitehead, Laurence (comps.), Transiciones desde un gobierno autoritario. Vol. 2 América Latina, Buenos Aires, 1988, pág. 254. 
sos como obra de "agitadores profesionales". Permanecían encarcelados los dirigentes sindicales y el aislamiento del gobierno llegó a su máximo nivel arreciando las denuncias por falta de libertades y atropello de los derechos humanos. La iglesia progresista cumplió un importante papel en estas denuncias, siendo el obispo de Cajamarca, monseñor Dammert, el más claro exponente de esta actitud.

Acción Popular no participó en las elecciones del 18 de junio de 1978 para la Asamblea Constituyente, pero reapareció en la escena política con un discurso de distancia respecto de los militares y autoproclamándose como "auténticos" defensores de la democracia. El PPC se presentó liderado por Bedoya Reyes, y quedó por debajo del $24 \%$ de los votos, lo cual fue considerado una derrota ante la ausencia de AP. El APRA alcanzó el 35\% de los votos y su líder, Víctor Raúl Haya de la Torre, fue elegido presidente de la asamblea.

La izquierda fue la que más sorprendió en estas elecciones alcanzando, entre sus diversas candidaturas, un significativo $36 \%$ de los votos. ${ }^{17} \mathrm{El}$ velasquismo trató de tomar vuelo con la constitución del Partido Socialista Revolucionario (PSR) liderado por el general Leonidas Rodríguez Figueroa, pero fue el Frente Obrero, Campesino, Estudiantil y Popular (FOCEP), dirigido por el profesor Genaro Ledesma Izquieta, el más votado entre la izquierda. En su filas se encontraban intelectuales independientes como Laura Caller o el escritor Manuel Scorza, pero su mayor atractivo político y electoral se lo daría el guerrillero Hugo Blanco, quien en 1962 había encabezado las luchas campesinas en La Convención y Lares (Cusco).

Durante esta peculiar transición a la democracia, en la que los civiles redactaron una nueva Constitución mientras los militares seguían gobernando sin mayores intromisiones, todos los actores trataron de ganar posiciones frente al futuro nuevo régimen. Aquí los proyectos ideológicos entraron en conflicto con las tácticas políticas y lo que pudo ser defendido ayer es modificado hoy, como la posición del APRA en torno al voto de los analfabetos que finalmente fue impuesto por los militares. La izquierda no aprobó la nueva Constitución y sufría para armar una oposición electoral unificada para las elecciones de 1980. Más fácil le resultaba enredarse en sus múltiples disputas de camarillas y personalismos, perdiendo su anterior gran capacidad de movilización. Para sorpresa de todos, el gran triunfador

17 Los datos han sido tomados de Pease García, Henry: Los caminos..., pág. 316. 
de esos comicios sería el que mantuvo mayor distancia del gobierno militar y de la Asamblea Constituyente: el candidato de Acción Popular, Fernando Belaunde Terry, barrería con un $45 \%$ de los votos válidos.

\section{La democracia y el conflicto entre expertos e ideólogos (1980-1990)}

\section{El gobierno de Acción Popular}

Luego del fracaso del velasquismo y la captura del gobierno por parte de los militares conservadores, el Perú presenció una ofensiva de la derecha aprovisionada de un discurso neoliberal para sustentar ideológicamente su proyecto político. Éste fue un marco propicio para la aparición de una serie de jóvenes intelectuales que se autodenominaban "nueva derecha", auspiciados especialmente por los periódicos La Prensa y Expreso, instituciones como Apoyo, el Instituto Libertad y Democracia (ILD), y revistas como Debate. Se trataba de personajes que irían creciendo en la escena pública peruana, como Juan Carlos Tafur, Pedro Planas, Jaime Baily, Fernando Iwasaki, Willy Quevedo. Todos ellos formados en la escuela de Pedro Beltrán ${ }^{18}$ reactualizada por intelectuales y políticos como Enrique Chirinos Soto, ${ }^{19}$ el famoso novelista Mario Vargas Llosa, Manuel D'Ornellas, Patricio Ricketts Rey de Castro, ${ }^{20}$ Hernando de Soto ${ }^{21}$ y Arturo Salazar Larraín, ${ }^{22}$ principalmente.

18 Pedro Beltrán fue representante de los sectores terratenientes más modernizadores de mediados del siglo Xx. Liberal a ultranza, llegó a ser ministro de economía en los años cincuenta. Además, fue dueño del diario La Prensa, al que dio un poderoso impulso como portavoz de los sectores que él representaba. Por otro lado, promovió a una serie de intelectuales y periodistas que después dejarían huella en los debates políticos peruanos.

19 Enrique Chirinos Soto perteneció al Partido Aprista, luego se incorporó al derechista Partido Popular Cristiano y en los noventa fue un miembro destacado del fujimorismo.

20 Manuel D'Ornellas y Patricio Ricketts Rey de Castro son agudos observadores de la vida política peruana, ambos pertenecían a la plana del diario Expreso, y el primero de los mencionados fue, incluso, director de dicho periódico.

21 Hernando de Soto es autor de dos libros fundamentales para comprender cómo piensa la elite más avanzada del neoliberalismo en el Perú: El otro sendero, Lima, 1985 y El misterio del capital, Lima, 2000. De Soto es un caso paradigmático del papel del experto: apoyó al gobierno de Belaunde en la simplificación administrativa, luego colaboró con el Partido Aprista en los aspectos de administración municipal y, finalmente, fue un apoyo del fujimorismo en sus primeros años, especialmente en su relaciones con los organismos financieros internacionales.

22 Arturo Salazar Larraín fue uno de los discípulos de Beltrán, y se caracteriza por su posición anticomunista. Llegó a ser director de La Prensa. 
La derrota del proyecto reformista del velasquismo y, en consecuencia, la retirada de los asesores con pretensiones ideológicas, abrieron las puertas a una nueva forma de gobernar y de entender los problemas que aquejaban al Perú. Había llegado el momento del "realismo", de las soluciones "prácticas" más allá de los costos sociales que pudieran ocasionar. La democracia era sinónimo — - según esta mirada- de eficiencia. Cualquier otra manera de enfrentar el gobierno era considerada como pura demagogia.

En esta forma de gobierno, la entronización de los expertos no fue difícil ni costosa para AP. Este partido carecía tanto de ideólogos como de un programa integral sobre qué hacer con el país. Más bien era un compuesto de poderes locales y hombres ligados al sistema financiero internacional que resolvían sus conflictos gracias al papel dirimente de su conductor, el propio Belaunde Terry. Aun sin ideología definida o discursivamente construida, AP se ubicaba en el centro-derecha del espectro político peruano.

Por las características del partido en el gobierno, e imbuida de cierto triunfalismo, la derecha peruana consideraba que los resultados electorales, con los que la sociedad había sancionado el triunfo de AP, significaban la impugnación de la política centrada en el Estado, característica del periodo velasquista básicamente. Por su parte, los empresarios peruanos pensaron que por fin era su hora, pues había llegado el momento de la confluencia entre el control del gobierno y una ideología legitimada socialmente ad hoc a sus intereses.

Como señala Catherine M. Canaghan, ${ }^{23}$ para los capitalistas nacionales en los Andes, el retorno de la democracia significó la oportunidad de resucitar sus instrumentos de influencia sobre los políticos. Como consideraban que los gobiernos militares estaban signados por la incertidumbre, la instalación de un gobierno constitucional les proporcionaría el marco jurídico que reclamaban, no sólo para implementar medidas económicas convenientes a sus intereses, sino también para definir el rumbo político de un gobierno que consideraban amigo. Esas fueron las razones principales que los llevaron a impulsar el llamado proceso de retorno a la democracia. Sin embargo, se trató de una esperanza frustrada, pues los grupos de intereses empresariales continuaron sin acceder a los procesos de decisión política.

23 Canaghan, Catherine M.: "Capitalists, Technocrats and Politicians: Economic PolicyMaking and Democracy in the Central Andes", Working Paper núm. 109, May, University of Notre Dame, USA, 1998. 
En efecto, durante el segundo gobierno de Belaunde, Manuel Ulloa el encargado de delinear la política económica y con una amplia experiencia en la banca internacional-, y su equipo de tecnócratas, decidían la política económica sin consultar a los partidos. Incluso se rodeó de economistas "repatriados" de los organismos internacionales como Roberto Abusada, quien fue viceministro de comercio, Carlos Rodríguez Pastor o Pedro Pablo Kuczynski, en las importantes carteras que tenían relación con las finanzas y la economía. Atendiendo más a los datos macroeconómicos, este grupo de expertos definió una política en la que lo central era la reducción del Estado y del gasto público, así como impulsar una economía de mercado. No obstante, el gobierno de AP, sólo aplicó tibiamente las recetas neoliberales, en gran parte por la oposición que encontró en su interior el propio partido en el poder. Los políticos "tradicionales", ligados a los cotos locales de poder, muy a la usanza de un viejo caudillismo, reclamaron para sí una mayor injerencia en la delineación de la política económica. Su argumento era muy simple: la aplicación de las medidas fondomonetaristas podía significar para el partido la pérdida de su militancia, que ya incluso empezaba a menguar.

El mismo Belaunde mantuvo una posición ambigua frente al proyecto de sus asesores. Más político que economista, Belaunde centraba su interés en el futuro de su partido, pues sabía que una aplicación radical de las recetas fondomonetaristas podía implicar una deslegitimación social de su gobierno muy grande. De esta manera, y en el interior de la pugna reseñada, la política económica del gobierno de AP se caracterizó por la ambigüedad de mantener ciertos niveles de injerencia en la economía por parte del Estado, al mismo tiempo que se impulsaba, erráticamente, una economía de mercado.

Dicha ambigüedad también debe ser explicada por la presencia corrosiva del grupo maoísta Sendero Luminoso, que le había declarado la guerra al Estado peruano desde mayo de 1980. Ello obligó al aparato estatal a utilizar sus pocos recursos para atender a las poblaciones andinas que eran las principales víctimas de la guerra. En otras palabras, el Estado se vio obligado a privilegiar ciertas demandas sociales que para la política neoliberal resultaban secundarias.

Por su parte, los ideólogos pertenecían en su mayoría a las fuerzas políticas de oposición: tanto ex-velasquistas como a los partidos de la nueva izquierda. Ésta había conseguido una importante legitimidad política gracias a su vinculación con los sectores populares organizados, incluso 
había llegado a ganar en las elecciones municipales de 1983 la alcaldía de Lima y de otras importantes ciudades del país.

En el terreno del pensamiento, desde las universidades y las Organizaciones No Gubernamentales, los intelectuales ligados a la izquierda - militante o ideológicamente - habían alcanzado una importante presencia pública, sustentada tanto en su aparición en los medios de comunicación como en la profusa publicación de libros de corte académico. En otras palabras, los intelectuales de izquierda habían conseguido constituirse en una voz importante en el debate público, pero desde la oposición.

En este contexto amplio, en el segundo gobierno de Acción Popular fue muy nítido el desencuentro entre el dogmatismo de los expertos neoliberales y la necesidad política de mantener ciertos niveles de legitimidad. El resultado fue catastrófico, pues el gobierno no dio solución ni a la crisis económica ni a la guerra civil. En este empantanamiento accedió al poder, en julio de 1985, el primer gobierno del APRA. Dicho partido trató de dar un viraje de la política implementada por Acción Popular, retornando a ciertas medidas populistas, al menos en sus dos primeros años de gobierno; los años justamente de sus mayores niveles de aceptación social.

\section{El gobierno del APRA: vuelven los ideólogos, pero no están solos}

El Partido Aprista desplegó, desde sus orígenes, un proyecto político que estuvo dirigido por intelectuales y políticos. Es decir, trató de anudar una fuerte voluntad de poder con la construcción de una visión global del Perú. Al lado de su gran líder - Haya de la Torre - se encontraban intelectuales (o intelectuales-políticos) de gran valía como Luis Alberto Sánchez, Antenor Orrego, Alberto Hidalgo, Manuel Seoane, entre muchos otros. En consecuencia, el aprismo fue, desde su nacimiento, una propuesta político-intelectual. A mediados de los años cincuenta dicho partido sufrió una importante mengua de su parte productora de pensamiento, pues luego de sus discutidos compromisos con la oligarquía un buen número de sus intelectuales más representativos renunciaron y pasaron a engrosar otros partidos como AP, la izquierda o decidieron quedar como pensadores "socialmente desvinculados".

El APRA jamás se pudo recuperar de esta sangría de sus hombres de pensamiento. Por ello, entre otras razones, la reflexión de ambición general fue desatendida y su programa, antes tan bien definido, empezó a adqui- 
rir contornos cada vez más confusos. De esta manera, el aprismo se limitó a la supervivencia política, pero sin renovar los sentidos de su actividad. El velasquismo, además, ahondó el alejamiento del proyecto aprista de una sociedad peruana que se modificaba sustancialmente por medio de las reformas del gobierno militar. Sólo después del retorno a la constitucionalidad, en 1980, el viejo partido peruano empezó - tibia e inconclusamente - a revalorar la importancia de la actividad intelectual dentro de su proyecto político. Pero ya las universidades habían sido hegemonizadas - si cabe el término- por los intelectuales de izquierda.

En estas condiciones el Partido Aprista accede al poder, dirigido por un líder joven, Alan García. Éste basó su éxito en que había sabido hábilmente navegar entre las disputas que distintas facciones fomentaron dentro del aprismo luego de la muerte de su fundador en 1979. Como resultado de una acción bifronte - conciliadora en algunos momentos y dura en otrosGarcía se empinó gracias a su oratoria y capacidad para catalizar el humor social de su momento y autopresentarse como encarnación de la esperanza de terminar con la crisis económica y la violencia política.

Ante la carencia de intelectuales propios, García apeló a aquellos que ya habían sido protagonistas durante el reformismo militar. Por un lado, incorporó a los ex-asesores del velasquismo - ahora agrupados en el Centro de Estudios para el Desarrollo y la Participación (CEDEP) que edita la importante revista Socialismo y Participación- como Carlos Franco, Federico Velarde, Francisco Guerra García, Hugo Neira, entre otros. Por otro lado, llevó al Perú al asesor argentino Daniel Carbonetto, economista especializado en temas de informalidad.

García había construido su discurso, primero, desde la oposición al segundo belaundismo y, luego, en su campaña electoral dirigiéndose a los informales, a los pequeños empresarios y a los campesinos, de manera fundamental. Con ello, le arrebató gran parte de la base social a la izquierda (agrupada en el frente Izquierda Unida) y transmitió una nueva forma de enfocar al sujeto que supuestamente debería atender prioritariamente el gobierno: ya no a los privilegiados de siempre, sino a los postergados también de siempre. En este panorama, dos propuestas sobresalían en el frente interno: atacar la pobreza de aquellos que constituían la base de la pirámide del ingreso y propiciar el desarrollo de las zonas marginadas, como el Trapecio Andino. En tanto la violencia política era vista como una emanación de las condiciones estructurales (afirmación que viene del discurso de la izquierda y que García incorporó al suyo), al dar solución a éstas se resol- 
vería aquélla. En el frente externo, la propuesta de García de limitar el pago de la deuda externa recobraba un discurso tercermundista y antimperialista. Parecía que el viejo aprismo se encarnaba en la figura del joven presidente.

Los dos primeros años del gobierno aprista hacía recordar en mucho a los del reformismo militar: prédica nacionalista en contra de los poderes económicos extranjeros, atención a las condiciones de pobreza y marginalidad de la mayoría del país, estímulo a la burguesía nacional, apelación al mestizaje, a los cholos, como base de la identidad nacional, etcétera. Es evidente que detrás del discurso pronunciado por García estaba el grupo de asesores que provenían del velasquismo. Su huella se puede detectar especialmente en los discursos de los dos primeros años de gestión. ${ }^{24}$

Es interesante mencionar que el gobierno aprista sirvió como escenario involuntario para la reactualización de los debates ocurridos en los años setenta, entre reformistas velasquistas (ahora apoyando al aprismo) y los de la izquierda marxista. Los intelectuales propiamente apristas casi no tenían voz en este escenario, quizás porque no tenían ideas que sustentar.

Desde la izquierda, espacios como El diario de marka, Amauta o revistas como El Zorro de Abajo y Márgenes, divulgaban una visión del Perú clara, específica, aunque en transformación: la del cambio estructural del país más allá del formato político (más adelante la importancia del tipo de régimen sería importante, cuando se asuma de manera paulatina el tema de la democracia desde las posturas marxistas). Desde el gobierno, era el propio presidente quien transmitía una forma de mirar el país que se entroncaba con las propuestas originarias del Partido Aprista y las posturas de los asesores del velasquismo. El gobierno no tenía una plataforma propia que transmitiera su ideología, y las que habían, los propios diarios oficiales como El Peruano o La Crónica, no alcanzaban a tener un impacto importante, además que éste último diario también contaba entre sus colaboradores con intelectuales de izquierda. De una forma exagerada, se puede afirmar que el presidente García actuaba como una especie de ventrílocuo que pronunciaba discursos que tenían sus orígenes en otros lugares. En efecto, con respecto al aprismo original, García había tratado de remozar su discurso fundador adecuando propuestas que venían de la izquierda, por un lado, y las que provenían del reformismo velasquista, al cual el propio aprismo había combatido, por otro.

24 Sobre el contenido y la función de los mensajes presidenciales, se puede consultar: Martín Sánchez, Juan: Perú 28 de julio... 
Luego de sus dos primeros años de gobierno en el que se respiró un cierto aire de estabilidad económica, el aprismo en el poder empezó a manifestar fuertes conflictos internos. García gobernaba de manera demasiado independiente de su propio partido y daba más confianza a sus asesores externos. Una manera de recobrar su liderazgo y afianzar su protagonismo fue el anuncio de una medida que, aunque audaz, terminó siendo el click que inició el fin del gobierno aprista. En 1987, el presidente presentó ante el congreso el proyecto de nacionalizar la banca. La falta de consenso entre los propios apristas, la opinión dividida de la izquierda en torno a la medida, que impidió un apoyo decidido, una opinión pública dubitativa y, por último, la articulación de la derecha, fueron circunstancias que impidieron que el proyecto de estatización se concretara.

Quizás el efecto más prominente de la medida frustrada fue el último de los mencionados: el recobrado protagonismo político de la derecha. Si durante el segundo belaundismo se conjuntaron esfuerzos de ciertas personalidades y de prospectos académicos, bajo el aprismo, a este interés intelectual, se sumó la gestación de una voluntad por el poder que se materializó en la conformación de un sujeto político: el Movimiento Libertad. Pero, además, encumbró a un personaje que venía de las canteras de la literatura, el escritor Mario Vargas Llosa. A diferencia de otros esfuerzos de la derecha peruana, el Movimiento Libertad se constituyó en el plató desgarrado de la política peruana de mediados de los ochenta, y desde él difundió una idea-valor: la defensa de la libertad. Si antes la derecha peruana había buscado propalar algún interés (el mercado, la riqueza, el libre comercio), ahora apelaba a un elemento que podía permitir la confluencia de los peruanos más allá de las disputas ideológico-políticas.

La libertad se constituyó en signo del nuevo movimiento que emergía e inundaba las calles. En efecto, cuando las banderas de la libertad fueron agitadas se abrió paso la oportunidad para que los peruanos pudieran ver, por primera vez, cuáles eran los rostros de los verdaderos dueños del Perú, antes agazapados detrás del sillón presidencial. Los hombres de carne y hueso del poder financiero salían para reclamar su lugar como actores políticos (aunque después volvieran a sus puestos habituales tras bambalinas).

Posteriormente, el Movimiento Libertad dio paso a la constitución del Frente Democrático (Fredemo), gracias a la alianza con los partidos tradicionales AP y PPC. La aparición de dicho frente ocasionó graves discrepancias entre los principales fundadores del Movimiento Libertad: Vargas Llosa y De Soto. Éste, opuesto a cualquier alianza con los partidos que 
representaban al pasado "mercantilista" (es su término), concluyó por separarse del núcleo original del movimiento.

Por esta razón fue el Fredemo el que lanzó la candidatura presidencial de Vargas Llosa para las elecciones de 1990 y que concluyó con la derrota electoral conocida. ${ }^{25}$ Esta nueva derecha se caracteriza por su crítica al Estado ineficiente, a los empresarios mercantilistas y por su creencia ciega en el libre mercado y en la libre competencia. Intelectualmente, obvia el proceso particular del desarrollo del pensamiento peruano para asimilarse a un discurso transnacional que incluso menosprecia las culturas particulares. Adam Smith, Milton Friedman, Von Hayek, Revel, Tumlir eran las principales fuentes en las que moldeaban su pensamiento, ${ }^{26}$ pero por momentos con tanto dogmatismo, intransigencia y fundamentalismo que hacían recordar a los militantes izquierdistas del decenio de 1970.

La ascensión de esta derecha renovada opacó el papel de los ideólogos que habían llegado auspiciosamente durante el gobierno aprista y que, al final de los ochenta, fueron identificados con el pasado populista, el radicalismo y la ineficiencia. Y algunas pruebas daban la razón a sus críticos, pues con el presidente García el Perú llegó a los niveles de inflación más grandes de su historia, el senderismo no pudo ser detenido e, incluso, aumentaba su terror, mientras la sociedad peruana se debatía en el caos, la desconfianza y el apoliticismo extremo. Ante este panorama se reclamaba un pragmatismo que tendría que cumplir con la imperiosa tarea de refundar al Estado y a la sociedad peruanos. Parecía que la nueva derecha estaba en condiciones de cumplir este plan, sin embargo, un actor inesperado irrumpiría en la escena político-electoral para reacomodar (o desacomodar, sería más justo decir) las reglas de la lucha por el poder.

\section{Los años ocultos del fujimorismo (1990-2000)}

Luego de su triunfo electoral en la segunda vuelta sobre Vargas Llosa, el prácticamente desconocido ingeniero Alberto Fujimori iniciaba su gobierno entre el desconcierto y la sorpresa. Ni él se imaginó ser ungido como presidente del Perú; sus aspiraciones eran más modestas: un lugar en el Senado peruano. Pero una serie de circunstancias, entre las que no estu-

25 Sobre la campaña electoral ver: Vargas Llosa, Mario: El pez en el agua, México, 1993

26 Durand, Francisco: "La derecha renovada", Márgenes, núm. 5 y 6, diciembre, Lima, 1989. 
vieron ausentes las revanchas entre actores políticos irreconciliables, permitieron que el pintoresco ingeniero llegara a Palacio de Gobierno. En efecto, luego de un inicio de campaña espectacular, Vargas Llosa se fue precipitando en la aceptación de los sectores populares que, desconfiando de sus evidentes ligazones con los eternos poderes nacionales e internacionales, volteó la cara y encontró a alguien más parecido a ellos, un inmigrante, un hijo del pueblo, que no les prometía grandes cambios pero tampoco les amenazaba con traumáticos programas de reforma estructural. A esto se añadió el fundamental apoyo electoral del APRA y de la izquierda - a la sazón dividida en Izquierda Unida (IU) y en Izquierda Socialista (IS).

Como Fujimori no estaba preparado para el triunfo, tampoco estaba listo para gobernar, sin embargo, supo moverse con habilidad y adaptarse a las presiones de los poderes fácticos. Sin programa, equipo ni ideas, pero con un firme propósito de consolidarse en el poder, el nuevo presidente acudió a ciertos personajes de la política peruana que encajaban dentro de las opciones ideológicas y políticas que lo habían apoyado con sus votos. Así, conformó su gabinete con miembros tanto de IU como de IS, incluso un ex-militante de Acción Popular, Juan Carlos Hurtado Miller fue nombrado primer ministro, mientras en el congreso la relación con la bancada aprista era cordial.

Tan cordial era que la colaboración del naciente fujimorismo con dicho partido impidió que se aprobara la investigación del ex-presidente García acusado de enriquecimiento ilícito. En esta primera etapa del fujimorismo no aparecía claro nada, ni ideología, ni proyecto, ni programa. El diseño de estos rubros se estaba operando fuera del alcance del público y la crítica. Pronto los militares le darían lo que necesitaba: el Plan Verde que, según se leía en sus páginas, refundaría la república ${ }^{27}$ Desde entonces se fue afianzando un burdo autoritarismo, ${ }^{28}$ corrupto y escaso de ideas.

Con respecto al tema que articula estas páginas, debemos señalar que el inicio del fujimorismo se debatió entre el mantenimiento de los ideólo-

27 Tapia, Carlos: Las Fuerzas Armadas y Sendero Luminoso: dos estrategias y un final, Lima, 1998.

28 Algunos de los libros que tratan sobre el fujimorismo son los siguientes: Degregori, Carlos Iván: La década de la antipolítica. Auge y huida de Alberto Fujimori y Vladimiro Monstesinos, Lima, 2000; Rospigliosi, Fernando: Montesinos y las fuerzas armadas. Cómo controló durante una década las instituciones militares, Lima, 2000; Cotler, Julio, y Romeo Grompone, El fujimorismo, ascenso y caída de un régimen autoritario, Lima, 2000; Bowen, Sally: El expediente Fujimori. El Perú y su presidente, 1990-2000, Lima, 2000; Crabtree, John, y Jim Thomas, El Perú de Fujimori, Lima, 1999, entre muchos otros. 
gos y la inclinación por los expertos. Los años subsiguientes, nos hicieron ver más nítidamente la opción del gobierno. Bajo la gestión de Fujimori, los intelectuales - con las características que hemos estado definiendo en tanto ideólogos-, prácticamente no encontraron espacio en la política para desarrollarse, a lo más, actuaron como funcionarios y propagandistas. Como señala Hugo Garavito, ${ }^{29}$ se trató del primer gobierno en el que los intelectuales de aspiraciones generales permanecieron excluidos del poder. Si se toma la terminología de Gouldner, ${ }^{30}$ se puede decir que los ideólogos cedieron el paso a la intelligentsia, esto es, a la tecnocracia.

En contra de las promesas de la campaña hacia la presidencia, el naciente fujimorismo asumió las ideas neoliberales que había combatido. La aplicación del shock económico, la dureza con que enfrentó al senderismo más allá de las formalidades en la defensa de los derechos humanos que habían mostrado los gobiernos anteriores, la lógica de mercado que imperó durante sus años de gobierno, los pragmáticos arreglos limítrofes con los países vecinos, las mal llamadas "reformas" de los principales poderes como el judicial y el legislativo (a los que cerró con el autogolpe del 5 de abril de 1992), entre otras medidas, nos indican que Fujimori iba definiendo las características de su gestión económica dentro de los parámetros neoliberales establecidos por los organismos financieros al mismo tiempo que instalaba un estilo autoritario que se cobijaba en la intervención de los militares leales a él y a su entorno y — lo sabemos ahora- bajo una costra de corrupción.

Este estilo pragmático de Fujimori, con la modalidad de resolver problemas aquí y ahora, dejó en un segundo plano la necesidad de definir algún proyecto de sociedad futura. La dimensión de largo plazo, cuyos representantes más prominentes son los ideólogos, fue remplazada por el momento inmediato. Por eso es que para el fujimorismo era tan central el secreto, el actuar de improvisto y por la espalda, sorprendiendo. En este estilo de política, la búsqueda de fórmulas de consenso resultaba írrita.

El cuerpo ciudadano, el demos, de alguna manera, estorbaba. Más conveniente era para el fujimorismo la articulación precaria de individuos atomizados, siempre al borde de la supervivencia. En un contexto de esta naturaleza, los intelectuales con pretensiones de totalidad terminaron sobrando. Los espacios naturales en el que se debían desenvolver (como la

29 Garavito, Hugo: “Después de Fujimori ¿qué?”, Unomásuno, 16 de abril, México, 1995.

30 Gouldner, Alvin W.: El futuro de... 
universidad o las ONG, por ejemplo) se debilitaron hasta casi extinguirse, sobre todo en las provincias. Los ideólogos del velasquismo y los pertenecientes a la izquierda prácticamente desaparecieron durante el decenio infame que fue el de 1990 para el Perú y, aunque siguieron en su labor de denunciar la naturaleza del fujimorismo, lo hacían desde tribunas con influencia acotada (casi no tenían acceso a los medios de comunicación).

Una incisiva red de agentes y tecnócratas del poder no elegidos públicamente (ni en elecciones ni por procedimientos legales adecuados) tomaban posiciones y suplantaban a una clases política amenazada, desorientada, sobornada o, simplemente, comprada. El abogado de narcotraficantes y militares con problemas, mundialmente conocido por su afición a los videos domésticos, Vladimiro Montesinos, controlaría el poder de fondo, el de las relaciones fácticas y personales, en demérito de las normativas e institucionales, con los militares, los comandos de asesinos y extorsión, los políticos corruptos, el mercado internacional de armas, el narcotráfico y el contrabando. Un auténtico "experto" del poder oculto y de la "antipolítica", como diría Carlos Iván Degregori. Este personaje ayudó al candidato a presidente en la segunda vuelta de 1990, Alberto Fujimori, a resolver algunos problemas con la justicia y conectarse con los nerviosos militares en medio de la guerra con Sendero Luminoso. Tras la estabilización económica, debido al grado cero en que Carlos Bologna (economista graduado en Oxford) llevó a la economía, y la captura de Abimael Guzmán, se radicalizaría la estrategia de poder en la sombra, teniendo como único objetivo político la reelección de Fujimori en 1995, primero, y luego en 2000. Con ésta se salvaguardaba la amplia red de corrupciones y delitos de toda índole en que había caído la clase política oficialista del Perú.

Pero si bien Vladimiro Montesinos fue el conductor principal de esta necrosis política, no estuvo sólo y en el juego llegaron a caer abogados tan reputados como Francisco Tudela y Fernando Trazengnies, ambos "afamados" expertos en relaciones exteriores, el hermano del presidente Santiago Fujimori, o la popular conductora del programa de televisión, "Laura de América", la modesta Laura Bozo, que haría un importante trabajo de propaganda burdamente encubierta. El fujimorismo sí tuvo "discurso" pero su elaboración no fue pública o sujeta a debate, sino oculta, mediante operativos de difamación nunca imputables a una fuente cierta, como funcionó con la llamada "prensa chica" pero también con la infiltración y captura de las televisiones y la amenaza a los periodistas e intelectuales que no se dejaban filmar con Montesinos. 
Todo se volvió un campo de disputa por el poder político pero el poder político estaba más ausente que nunca, se imponía el secreto y la relación privada; el reposo necesario para la reflexión era imposible de conseguir. En este sentido, hasta los intelectuales con mayores pretensiones de generalidad se transformaron en potenciales personajes políticos. Nunca como durante el gobierno fujimorista el campo intelectual-académico fue tan poroso e inútil. En el nuevo siglo esta herencia es pesada, y una reformulación del papel de los intelectuales generales en la sociedad peruana se vuelve imperativa.

\section{Observaciones sobre el periodo}

Una primera cuestión a señalar es que nuestro estudio toma como inicio los años de mayor auge intelectual en el Perú y América Latina desde el comienzo de siglo XX, entendiendo esto como la envergadura (cuantitativa y cualitativa) de la discusión ideológica. Pero si bien en las dos primeras décadas del siglo se podría detectar un protagonismo de los pensadores liberales y conservadores - Víctor Andrés Belaunde, José de la Riva Agüero o Francisco García Calderón, devotos de José Enrique Rodó-, en los años sesenta y setenta el debate está dominando, cuanto menos, por el léxico izquierdista. ${ }^{31}$ De aquí se puede extraer, por una parte, la imagen del declive desde ese momento álgido en que, incluso, tuvieron una mayor influencia en las políticas estatales y, por otra, la dificultad para aceptar como intelectuales ideólogos a aquellos que no correspondan con el modelo del intelectual comprometido de la izquierda. Unido a esto último, estaría el esfuerzo desarrollado durante los años ochentas en el Perú por crear una figura de ideólogo liberal, que tan francamente asumiría Mario Vargas Llosa o Hernando de Soto.

Una segunda cuestión, derivada de la anterior, sería la percepción de que los intelectuales ganarían influencia y protagonismo durante los gobiernos reformistas y abiertamente centrados en el mayor papel del estado - los de Velasco y García-, mientras que en los gobiernos de retroce-

31 Valga como nota la opinión de Sinesio López que no encontraba rastro alguno de pensamiento político de derechas posterior a los años treinta: "El estado oligárquico en el Perú: un ensayo de interpretación", en El Dios mortal. Estado, sociedad y política en el Perú del siglo XX, Instituto Democracia y Socialismo, Lima, 1991; e "Intelectuales y políticos en el Perú del siglo XX", en Adrianzen, Alberto (Ed.), Pensamiento político peruano 1930-1968, Lima,1990. 
so del estado - Morales Bermúdez-o liberal-conservadores — Belaunde Terry - serían los expertos los que camparían por sus fueros. Pero ésta es una percepción demasiado marcada por la imagen dominante del intelectual comprometido de los años setenta, pues los expertos tuvieron un peso importante en todos los gobierno, aunque, tal vez, con menos publicidad. Habría que pensar en Otoniel Velasco en el Instituto Nacional de Planificación durante el velasquismo o Daniel Carbanetto durante el gobierno aprista, y no sólo en Silva Ruete y Moreyra para el gobierno de Morales o Pedro Pablo Kuczynski para el de Belaunde. En cualquier caso, estos dos últimos gobiernos habrían tenido una actitud menos favorable al discurso intelectual y más favorable al pragmatismo.

Una última cuestión a destacar en este recorrido es el carácter igualmente anti-intelectual y anti-experto del gobierno de Alberto Fujimori. En él - pasado el primer año de envenenada convocatoria al acuerdo nacional- tanto los tecnócratas, Carlos Boloña, o empresarios, Jorge Camet, como los pocos intelectuales que se arriesgaron en sus tenebrosas aguas, Marta Hildebrant o Fernando Trazengnies, acabaron engullidos por la lógica del secreto y el soborno. El FMI o el Banco Mundial tenían, incluso, que enviar a sus expertos junto con los programas de ajuste porque el Estado peruano no disponía de sus propios funcionarios de alto nivel, dándose la paradoja de que la parte peruana en las negociaciones sobre su deuda externa estaba representada por expertos formados o directamente pagados por el FMI.

Algo que tienen en común los intelectuales y los expertos, contra algunas opiniones precipitadas, es que los dos necesitan de la política y de los políticos, por mayor que sea el autoritarismo reinante; de lo contrario, el secreto, la antipolítica, como la denomina Carlos Iván Degregori, usurpa los ámbitos de lo público y lo privado dejando al cinismo fáctico como única legitimación posible. 